\title{
СВОБОДА СЛОВА И ПЕЧАТИ В ПЕРИОД ПЕРЕСТРОЙКИ НА ПРИМЕРЕ КРАСНОЯРСКОГО КРАЯ
}

\author{
Кобыжакова Ульяна Васильевна \\ студент магистратуры \\ ОЧУВО «Международный инновационный университет» \\ г. Красноярск
}

\begin{abstract}
Аннотация. Статья посвящена анализу социальных изменений, которые произошли в период Перестройки в СССР на примере Красноярского края, в частности изменения в средствах массовой информации под влиянием общественно-политических изменений. Период перестройки с большой очевидностью показал, что глубинные изменения в жизни общества являются весомым фактором в политической жизни страны. В переходные периоды истории в большей степени общество превращается в ту самую реальную политическую силу, которая способна определить дальнейшую судьбу всей страны.
\end{abstract}

Ключевые слова: СМИ, СССР, РСФСР, Перестройка, ускорение, политическая система, Красноярский край, социальное развитие, свобода слова и печати.

После январского Пленума ЦК КПСС, состоявшегося в 1987 г., кардинально изменилась политика партии во всех сферах жизни общества, включая и средства массовой информации. Ключевым понятием стала гласность. Впервые о ней заговорили на XXVII Съезде КПСС в феврале 1986 г.

Сутью политики гласности стало снятие существовавших многочисленных информационных запретов. С 1987 г. самыми обсуждаемыми в СМИ вопросами являлись: эпоха правления Сталина, привилегии парт номенклатуры, бюрократизм советской государственной машины, экологические проблемы. На страницах газет и журналов, в телевизионных и радиопрограммах отражалась реальная жизнь с ее достижениями и противоречиями, во всем многообразии различных мнений и суждений и на страницах красноярских периодических изданий стала появляться не только одобренная государственным аппаратом и 
идеологическими предпосылками информация, но и проявления свободы творчества журналистов.

Однако стоит отметить, что не все журналисты, получившие свободу слова, сразу пришли к пониманию этики и соблюдения элементарных норм морали и нравственности - многие представители средств массовой информации пришли к выводу о том, что смена политического режима - это повод очернить предыдущий, поэтому перестроечный период прежде всего для красноярских, как и для многих других региональных СМИ характеризуется очернением советского прошлого, сенсационными разоблачительными статьями и расследованиями.

Вместе с тем много было и более осторожных публикаций, допускающих, что возвращение старого режима еще возможно, поэтому статьи и публикации в начальный перестроечный период могли вставать в оппозицию с появившимися на страницах СМИ борцами за свободу слова и творчества.

Вместе с тем стоит отметить, что и интерес горожан к прессе сильно вырос. Одно из наиболее известных красноярских СМИ, «Красноярский комсомолец», в те дни публиковало наиболее злободневные материалы. В.П. Авдюков писал о редакторе Комсомольца, Л. Батынской: «Долгие годы удавалось здешним деятелям замалчивать молодежные проблемы, не выносить сор из избы, а мусору-то обнаружилось многовато: и по пьянству, и по разгильдяйству на работе, по увеселительно-оздоровительным делам города наш комсомол отставать от столицы не хотел. Обнаружились и проституция, и наркомания, и происки дельцов на руководящих постах. Молодежная газета не отмалчивалась, она ставила и ставит острые вопросы, добивается разрешения их» [1, с. 54].

Одна из таких статей была опубликована в 1990 г. Статья называлась «Мир наших раздумий». Впервые на страницах советской газеты публично выставляюсь все те проблемы, которые были в стране «.. .по территории страны мы первые...по численности армии первые...но совсем недавно узнали, что мы первые по многим показателям: по разводам браков, пьянству, курению, абортам, чуть ли не первые по самоубийствам, безусловно первые по бюрократизму» [1, с. 54]. Статья открывала глаза на многие проблемы, которые были скрыты многие года.

К концу 1980-х гг. расцвет понимания свободы слова в красноярских СМИ достиг своего максимума, поскольку даже партийные СМИ позволяли 
себе публикации достаточно смелых материалов.

Встреча на высшем уровне - визит Горбачева к высшему составу ЦК КПСС - послужил поводом для того, чтобы представители СМИ также нанесли визиты к местным партийным ячейкам и их руководителям, в рамках новых стандартов взаимоотношений СМИ и государственного аппарата.

Так, в январе 1989 г. состоялась пресс-конференция СМИ и О. Шеина, на которой руководитель краевого комитета партии заявил о важности и необходимости укрепления взаимоотношений партии и печати, поскольку перестройка сопровождалась значительной идеологической подготовкой граждан страны к грядущим реформам и изменениям [2, с. 29] .

В конце 1980-х гг. в регионе всего существовало более 100 газет, которые выпускались общим тиражом более миллиона экземпляров только в Красноярский край уходило более полутора миллионов экземпляров СМИ, а также более четырех миллионов журнальных изданий распространялось в города.

Заявление О. Шеина о необходимости налаживания взаимоотношений политического аппарата и СМИ содержало в себе и другой аспект влияния перестроечного периода - до 1987 г. упоминание о проблемах в политическом аппарате страны, а также освещение этих вопросов в СМИ не представлялись возможными в силу идеологических догматов и тотальной подчиненности периодики, радио и телевидения партийным органам. Однако теперь, власти открыто призывали к нахождению конфликтных точек и их устранению [7, с. 106].

Из более, чем двадцати партийных комитетов, которые регулировали деятельность СМИ, ответа и разрешения на публикацию того или иного материала сотрудники печати могли добиться только у семи. В журналистской среде более половины журналистов сами состояли в партии, а также среди сотрудников печати регулярно проводились «партийные чистки» и отслеживание политических взглядов и соответствия господствующей идеологии сотрудников печати.

Политический аппарат не мог существовать без мощной поддержки средств массовой информации, в связи с чем полная их подконтрольность постепенно стала одной из важных составляющих проводимой политики. Лояльность к режиму, скрытие фактов, порочащих авторитет партийных служащих и многое другое, долгое время оставались ведущими направлениями советских СМИ. Однако важно отметить, что, несмотря на 
идеологические и творческие ограничения, журналисты обладали высоким уровнем профессионализма, что выражалось в создании передач, посвященных другим аспектам повседневной жизни. Также в пользу краевых журналистов может говорить неоднократное награждение их призами международного уровня.

После начала кампании по расширению гласности в краевом радио- и телеэфире также стали появляться передачи, посвященные дискуссионным вопросам. Возрождению подвергся прямой эфир, и люди становились прямыми участниками телерадио передач. Среди общественно-политических передач появились программы, рассказывавшие и пропагандировавшие новую политику государства - «Взятка. Факты и размышления», «Ускорение», «Госприемка. Борьба за качество» [6, с. 116].

Что касается телевизионных передач краевой телестудии, то сюда входили «ИКС», «День края», которые являлись новостными программами, и выходили каждый день, освещая при этом также события местного характера. Кроме новостей, редакция обзавелась и такими информационными передачами как «Пешеход, дорога, водитель», тележурнал «02». Более половины информационного вещания строилось на комментированных сообщениях, для чего при отделе информации был создан штат комментаторов. Появилась передача «Актуальное интервью», в которой с местными знаменитостями обсуждали актуальные на тот момент времени темы. Также на телевидении был введен цикл передач «Открытое собрание», которые представляли собой своеобразный телевизионный мост, объединяющий в процессе прямого эфира три различные аудитории, принимающих одновременное участие в обсуждении важнейших проблем края. Помимо этого, с середины 1980-х гг. был введен цикл передач «Как помочь делу?». Программу вели совместно с редакцией промышленности крайкома КПСС. Под наблюдением журналистов находилось четыре краевых завода: автоприцепов, комбайновый, тяжелых экскаваторов и Минусинский электро комплекс. Каждому заводу было посвящено по три передачи, в итоге чего проблемы каждого из них были рассмотрены через призму видения рабочего, инженера, партийного работника. Итогом передач становилась встреча коллектива завода с представителями соответствующих министерств и главков.

С началом проведения в жизнь политики гласности расширилась тематика детского и молодежного вещания на Центральном радио и 
телевидении, что привело к возникновению цикла передач, посвященных семейному воспитанию, проблемам взаимоотношения родителей и детей. Такими передачами стали «Взрослым о детях», «В кругу семейном», «Радиостудия-73». В редакцию приходили письма от радиослушателей, в свою очередь на их вопросы отвечали специалисты различных профессий от психологов до писателей.

Важным событием в начале 1990-х гг. стало открытие независимых радиостанций «Эхо Москвы» и «Радио России», которые стали проводниками альтернативной точки зрения. Также стоит отметить, что в этот период в Москве, а также в Санкт-Петербурге, Самаре, Волгограде, Нижнем Новгороде, Тольятти, Владимире, Красноярске и Южно-Сахалинске начала вещание первая независимая российско-французская радиостанция «Европа Плюс», основное содержание передач которой составляли музыкальные программы, выступления наиболее популярных исполнителей. Это стало абсолютно новым форматом для российских радиослушателей.

Художественное телерадиовещание пополнилось целым спектром новых программ, среди которых были «Аншлаг», «Программа А», «Музыкальный ринг», «Поле чудес». Данные телепередачи носили в основном развлекательный характер и были призваны скорее смягчить обстановку в стране посредством юмора, искусства и т.д.

С 1980-х гг. характер культурно-просветительских передач изменился и на краевом радио и телевидении. Важно отметить, что в 1981 г. родилось движение «Превратим Сибирь в край высокой культуры!». На протяжении всего десятилетия шло неустанное разъяснение и пропаганда движения.

Театральные спектакли и выступления коллективов художественной самодеятельности постепенно вытеснялись фестивалями и концертными шоу профессиональных артистов эстрады. Основной темой культурнопросветительских передач краевого радио и телевидения стал поиск культурных особенностей региона. В передачах стали обсуждаться вопросы исторических традиций сибиряков, а также обращение к проблемам коренных народов Севера. Поддерживая уже известных краевых авторов, телерадио службы постоянно открывали новые таланты молодых красноярских песенников и литераторов. Примером передач такого характера, может служить музыкальная программа краевого радио «Дорогие мои земляки», где раскрывались музыкальные таланты нашего города $[3$, c. 54$]$. 
В 1982 г. начал свою экранную жизнь в Норильске цикл «Читай-город» - дискуссия молодых людей о проблемах, поднятых в литературе. Первые встречи с повестью Г. Щербакова «Дверь в чужую квартиру», затем с повестью Ю. Якименко «Сочинение» стали предметом обсуждения острых нравственных проблем поведения человека в обществе. В диспуте участвовали авторы этих произведений.

Как и прежде, выходили традиционные радиопередачи «Искусство и жизнь», «Красноярск литературный», «Шла война народная», передачи о народной классической музыке, концертные программы. Появилась новая музыкальная программа «Час пик», которая выходила раз в месяц и была посвящена проблемам современной легкой музыки, воспитанию музыкальных вкусов молодежи [4, с. 56].

К указанному периоду времени с радио сотрудничали почти все концертрирующие музыканты и коллективы Красноярской государственной академии музыки и театра. Просветительской деятельностью занимались известные красноярские музыковеды Людмила Гаврилова и Павел Юхвидин, композиторы Олег Проститов, Олег Мермкулов, Валерий Бешевли и многие другие.

Постепенно возрождался прямой эфир, в рамках которого слушателей и зрителей привлекали к непосредственному обсуждению тех или иных вопросов. Одними из первых в рамках прямого эфира на радио стали работать редакторы и ведущие молодежной редакции. В рамках программы «Молодость Енисея», в студию звонили жители города и ставили или принимали участие в вопросах, касающихся самых различных тематик. Также со второй половины 1980-х гг. в эфире «Молодости» зазвучали остросовременные музыкальные композиции. «Композиции отечественных рокеров, как российских, так и наших, красноярских, лучшие зарубежные команды - именно этот музыкальный материал стал нашим «трендом» .

Постепенно в телепередачах культурно-просветительской и детской направленности начинали появляться фильмы и мультфильмы зарубежных стран. Например, на новогодних каникулах 1991 г. впервые были показаны мультфильмы из серии «Уолт Дисней представляет». В небольшом количестве и на короткий промежуток времени стали доступны передачи о религии, религиозных течениях.

В молодежной редакции был введен цикл передач «Телефон доверия». Передача полностью строилась на диалоге со зрителем. Весь цикл 
представлял собой доверительный разговор журналистов со зрителями по волнующей красноярцев проблемам жизни и перестройки.

Именно с 1988 г. постоянным явлением в жизни телевидения, как центрального, так и местного стала реклама. В среднем реклама занимала 2530 минут эфирного времени в неделю. Было создано, по существу, первое ток-шоу на Красноярском телевидении - «Товары для всех». В студию привозилась продукция местных заводов, приглашались представители трёх сторон, производителей, торговли, покупателей. Вокруг сковородок КраМЗа или электроплиток Сибтяжмаша разыгрывались нешуточные страсти. Покупатели голосовали жёлтыми, красными и зелёными карточками. Каждая из них соответствовала определенному количеству баллов. По итогам голосования жюри и определяло, чей товар лучше [5, с. 7].

Таким образом, мы можем сделать вывод о том, что радио и телевидение на протяжении всего своего существования в СССР играли роль культурно - просветительского проводника для своих слушателей и зрителей. Повышая образовательный уровень людей, электронные средства массовой информации также старались знакомить их с лучшими произведениями отечественной литературы, музыки и театра. Также, именно благодаря региональным телерадио службам жители городов и сел могли познакомиться с произведениями местных авторов. Важно отметить, что до середины 1980-х гг. передачи культурно-просветительского характера занимали самый большой объем вещания среди остальных редакций. Однако, с началом политики гласности и перестройки, передачи общественнополитического характера стали лидировать. Это можно объяснить в первую очередь, произошедшими в стране изменениями на политической арене, а также открытию ранее запрещенных тем. Однако передачи культурнопросветительского характера также перестроились под тематику нового мышления. Теперь по радио и телевидению звучали произведения не только отечественных авторов, но и лучшие зарубежные композиции. Произошедшие в период перестройки изменения в тематике эфирного времени способствовали переходу телерадио служб на новый уровень развития, открыв новый этап в их истории.

Что касается редакций местного вещания, то важно отметить, что и здесь поднимались ранее запрещенные темы, а сами передачи перешли к новым формам подачи материала. Например, в Игарском городском радиовещании ведущее место занимал цикл передач «Перестройка и мы». Посредством разнообразных форм вещания и общения с представителями 
политических структур, журналисты старались показать основные требования перестроечного времени, среди которых особо выделялся тон «начать с себя», относящийся в первую очередь к руководительскому составу различных организации и предприятий.

Таким образом, мы можем сделать вывод о том, что передачи общественно-политической и экономической направленности прошли путь от простого освещения работы партии и промышленных объектов, до критики существующей системы и поднятия дискуссионных вопросов. Телерадиовещание, начиная с 1991 г., встало на путь максимальной приближенности к европейским аналогам, включая в себя не только информационные выпуски новостей, но передачи, которые могли показывать гражданам отличную от официальной, точку зрения. За 5-6 лет появилось большое количество новых теле- и радиопередач, которых за все время существования советского телевидения не было даже в планах, что привело к дальнейшему развитию электронных средств массовой информации в 1990-х г., но уже в качественно новом формате.

Конец 1989 г. знаменовался наличием в Красноярске двух наиболее крупных изданий - это были газеты, которые на тот момент еще оставались органами краевого комитета ВЛКСМ и КПСС - это были газеты «Красноярский комсомолец» и «Красноярский рабочий». Их тираж составлял от 250 до 300 тысяч экземпляров, а периодичность издания, соответственно, трижды в неделю и еженедельно .

Очень большое значение для развития красноярских СМИ имел Закон СССР от 12.06.1990 N 1552-1 «О печати и других средствах массовой информации», который был принят 12 июня 1990 г. Этот закон подразумевал как документальную, так и фактическую отмену цензуры, а также разрешение печати на создание собственных органов управления, а также собственной законодательной базы для СМИ края.

1990-1991 гг. для Красноярского края - это период активного роста количества новых средств массовой информации - только за второе полугодие 1990 г. и начало 1991 г. в Красноярском крае было основано 58 новых изданий городского, регионального и местного уровня .

Органы власти, в свою очередь, старались нарастить взаимоотношения со СМИ. В 1989 г. была издана новая газета «Вечерний Красноярск», которая быстро стала одним из признанных изданий города и основным «оплотом» начинающейся демократии. 
Газета впервые вышла в конце 1989 г. Учредителем ее стал красноярский горком. Тираж газеты доходил до 300 тыс. экземпляров. Газета сменила в период своего существования несколько редакторов, но всегда газета старалась выполнять свои функции как одного из ведущих общественно-политических СМИ города и края.

Инициатором создания этого издания стал В. Юрчик, а первым редактором - О. Клешнин, который до этого работал на посту заместитель редактора в «Красноярском рабочем». Основной состав редакции был укомплектован компетентными профессиональными журналистами, а сама газета стала фактически символом демократии, поскольку на ее страницах могли печататься обращения совершенно разных людей - от политических деятелей, до врачей и учителей [1, с. 54] .

Свобода печати впервые позволила начать переводить Красноярские издания на коммерческие рельсы - СМИ стали, так же, как и простые граждане, стараться усвоить правила существования коммерческого свободного рынка, что породило борьбу за целевую аудиторию. Это во многом объясняет наличие большого количества обличающих материалов не все они были результатом возникшей свободы слова, часть была коммерческим, заказным материалом, позволявшим СМИ выжить в новых условиях.

Многие СМИ из-за концепции «борьбы за правду», погони за сенсациями и обличениями, стали конфликтовать с политическими руководителями и общественными деятелями вплоть до судов.

Тем не менее, до того, как устоялся режим правления Ельцина, местные газеты довольно осторожно обращались с политической тематикой, предпочитая вопросы коррупции и социальной несправедливости. Так, «Вечерний Красноярск» печатал не более 5\% политической информации от своего объема, в основном это были новости.

К ветеранам печати и сотрудникам «ВК» прежде всего, относили В. Рубе, Р. Александрова, В. Евграфов, художник А. Фахразиев, фотокорреспондент А. Орешников.

Как только сало понятно, что «оттепель» в отношении СМИ не заканчивается, а только набирает обороты, партийное руководство из выжидательной позиции перешло к пассивному наблюдению за развертыванием деятельности СМИ. 
Одно из значимых событий в среде красноярских СМИ стало создание «Красноярской газеты», которая стала выходить три раза в неделю. Созданная по инициативе писателя О. Пащенко, газета имела не только характер общественно-политической, но и литературной. Ее редакция включала в себя как журналистов, так и писателей, и представителей культуры.

Направленностью издания стал лозунг ученого М. Северьянова «Государственность, народность, патриотизм», под которым она и существовала в период перестройки. Газета поддерживала моральные и нравственные ценности, способность к диалогу с политическими партиями и представителями религий.

Путч 1991 г. привел к тому, что ГКЧП был закрыт, газета тоже, но уже в октябре была восстановлена под тем же названием. На момент начала 1990$\mathrm{x}$ гг. она была практически единственным серьезным оппозиционным изданием, благодаря чему на ее страницах публиковались мнения известных оппозиционеров - Жириновского, Зюганова, Проханова и др.

1991 г. - год роста зарегистрированных изданий. К концу 1991 г. их количество выросло до 142-х, но при этом ситуация конкуренция и выживания приобретает поистине катастрофические масштабы - расходы на печать за счет инфляции увеличились практически вдвое, а тиражи начинают падать при одном и том же уровне авторского гонорара .

Тиражи центральных изданий в 1991 г. падают на 20.000 экземпляров, а тиражи журналов - с 4 млн. до 2,5 млн. экземпляров. «Свой голос» и «Красноярский комсомолец» занимают оппозиционную власти позицию, а про правительственная газета «Красноярский рабочий» не печатает опровержений, и не защищает власть и новый устав газеты имеет пункт, согласно которому политические лидеры не могут заставить газету публиковать что-либо или отклонять утвержденные редакцией материалы. Т.е. про правительственное СМИ отрицало прямое влияние власти.

Этот конфликт знаменует начало полного разрыва взаимоотношений красноярских СМИ и власти. К моменту путча СМИ края были полностью готовы прекратить взаимоотношения с политической властью в принципе, но теперь СМИ были вынуждены искать способы самоопределения и окупаемости с помощью поиска собственной постоянной аудитории.

Таким образом, мы можем сделать вывод, что средства массовой информации на территории Красноярского края в период перестройки 
прошли достаточно большой путь в развитии. В начале периода СМИ продолжали ограничиваться статьями о происходивших стране событиях, продолжали воспевать подвиг советского человека. Однако, открытость СМИ перед огромным количеством информации, порожденная свободой слова и падением «железного занавеса», повлияла на их качество возможность экспериментов, отсутствие цензуры и временное отсутствие законодательной базы спровоцировало рост откровенно аморальных материалов, которые увеличивали рост аудитории и прибыли СМИ. Красноярская газета в этих условиях старалась сохранять культурные и моральные ценности, хотя и проигрывала по сравнению с другими изданиями. Значимыми областными и краевыми газетами оставались в период перестройки 4 издания. В данный период времени рост Красноярских СМИ был достаточно высоким. На момент перестройки из 75 наиболее крупных городов России Красноярск по тиражам общественно-политических СМИ занимал 16-е место, и 47-е по уровню доступности негосударственных СМИ.

\section{Список литературы}

1. Авдюков Ю. П. Красноярская пресса - XX-XXI век. Сборник материалов по истории СМИ Красноярского края. - Красноярск, 2010. - 214 c.

2. Адамович М.Е. Из истории Красноярского государственного радиовещания // Культура и искусство сибирского города: традиции и современность: сб. науч. трудов. - Красноярск, 2012. № 3. - С. 29-33.

3. Бердников Л. П. Вся красноярская власть. - Красноярск, 2011. - 198 c.

4. Елинская, Т.Н. Говорит и показывает Красноярск. - Красноярск, 2012. $-56 \mathrm{c}$.

5. Златковский М. Мир наших раздумий // Красноярский комсомолец. - 1990. - № 43. - С. 7.

6. Зорина О.А. Красноярское краевое телевидение и радио: очень личная история. - Красноярск, 2012. - 116 с.

7. Никуленков В. В. Деятельность краевых и городских печатных СМИ г. Красноярска в контексте политики перестройки в 1989 - 1991 годах // Молодой ученый: 2010. - №8. - Т. 2. - С. 106.

(C) У.В. Кобыжакова, 2021 